1. FCPS

Senior Registrar Department of Ophtholomology

Ghazi Khan Medical College, DG Khan.

2. FCPS, FVRO, MRCSEd

Assistant Professor Department of Ophtholmology Lahore General Hospital, Lahore.

3. FCPS

Assistant Professor

Department of Ophtholmology Lahore General Hospital, Lahore.

4. M.Phil

Demonstrator

Department of Pharmacology

Lahore Medical and Dental College, Lahore.

5. FCPS

Senior Registrar

Department of Pharmacology

Ghazi Khan Medical College, DG Khan.

6. MBBS

PGR

Department of Dermatology

Inmol Hospital, Lahore.

Correspondence Address:

Dr. Muhammad Shaheer

48-B, Tec Town, Satiana Road,

Faisalabad.

mshaheer212@gmail.com

Article received on:

03/07/2019

Accepted for publication:

25/09/2019

\section{CHANGES IN INTRA OCULAR PRESSURE AFTER PHACOEMULSIFICATION WITH INTRAOCULAR LENS IMPLANTATION.}

\begin{abstract}
Rizwan Ahmed ${ }^{1}$, Muhammad Shaheer ${ }^{2}$, Arooj Amjad ${ }^{3}$, Talha $^{4}$, Hina Mehmood ${ }^{5}$, Ayesha Ahmad ${ }^{6}$
ABSTRACT... Objectives: To study the changes in intra ocular pressure (IOP) after phacoemulsification with intra ocular lens implantation. Study Design: Quasi experimental study. Setting: Lahore General Hospital, Lahore. Period: From 1-3-2017 to 30-9-2018. Material \& Methods: The study was conducted after getting approval from "Ethical Review Board" of Lahore General Hospital, Lahore. Patients presenting to the Eye OPD Lahore General Hospital were assessed for inclusion and exclusion criteria. All patients $(n=)$ diagnosed with cataract significantly decreasing vision were selected. Patients having any coexisting ocular pathology i.e. corneal opacity, Glaucoma etc. were excluded from study. Pre operatively intraocular pressure was measured on slit lamp with the applanation tonometry. The patients were called for follow-up after at which time Visual acuity and intraocular pressure was again measured and findings recorded in the proforma. All the surgeries were performed by single surgeon. Results: Pre-operative mean intra ocular pressure was $22.02 \pm 1.403 \mathrm{~mm} \mathrm{Hg}$ which reduced significantly to $20.39 \pm 1.363 \mathrm{~mm} \mathrm{Hg}, 19.61 \pm 1.418 \mathrm{~mm} \mathrm{Hg}, 18.94 \pm 1.738 \mathrm{~mm} \mathrm{Hg}$ after one day, one week and one month of surgery respectively. Conclusion: Phacoemulsification cataract surgery leads to a decrease in intraocular pressure.
\end{abstract}

Key words: Intra Ocular Pressure, Phacoemulsification, Tonometry.

Article Citation: Ahmad R, Shaheer M, Amjaad A, Talha, Mehmood H, Ahmad A. Changes in Intra Ocular Pressure after Phacoemulsification with intraocular lens implantation. Professional Med J 2019; 26(12):2201-2205.

DOI: 10.29309/TPMJ/2019.26.12.3895

\section{INTRODUCTION}

Cataract surgery is one of the most frequently executed surgeries around the globe. In this surgery the opaque cataractous lens is removed and is replaced by an artificial intraocular lens. ${ }^{1}$ The history of cataract surgery goes back two centuries where it started as couching in this part of the world. It was improved to extracapsular cataract extraction providing capsular support for the implantation of intra ocular lens. ${ }^{2,3}$ Currently, phacoemulsification is the surgery of choice for cataract due to its minimal per and Post-operative complications and an early visual recovery with better patient comfort. ${ }^{4,5}$

The effect of phacoemulsification on intraocular pressure has been reported in both glaucomatous and non-glaucomatous patients. ${ }^{6}$ The purposed mechanism is widening of irido-ciliary angle. ${ }^{7,8}$

The goal of this study was to observe the effect of phacoemulsification on dynamics of Ocular pressure of non-glaucomatous Pakistani population. Absence of local literature on this topic was the rationale to conduct this study.

\section{METHODOLOGY}

Ethical approval of the study was obtained from "Ethical Review Committee" of Lahore General Hospital, Lahore. Patients presenting to the Eye OPD Lahore General Hospital were assessed for inclusion and exclusion criteria. All patients $(n=)$ diagnosed with cataract requiring surgery were included in study. Patients having any coexisting ocular pathology i.e. Corneal opacity, Glaucoma etc were excluded from study. Pre operatively intraocular pressure was measured on slit lamp with the applanation tonometry.

After aseptic measures, opsite was applied on the eye to be operated and stab incision was made at the limbus. Viscoelastic was injected into the 
anterior chamber and continuous curvilinear capsulorhexis was performed. The lens nucleus was separated from lens cortex and lens cortex was separated from lens capsule by hydro dissection and hydrodilineation. The lens was the emulsified by phacoemulsification and an intraocular lens was implanted. Post-operative steroid and antibiotic drops were given every 4 hours for two weeks and 4 times daily for the next two weeks. The patients were called for follow-up after at which time Visual acuity and intraocular pressure was again measured and findings recorded in the proforma. All the surgeries were performed by single surgeon.

All data analysis was carried out on SPSSP version 22 for windows. Quantitative variables were Mentioned as mean and standard deviation values, however the qualitative variables were mentioned as frequency and percentages. Bonferroni Post Hoc Test was applied to determine the difference between Intraocular pressure PreOperatively and Post-Operatively. P-value $\leq 0.05$ was considered as statistically significant.

\section{RESULTS}

Majority of patients were male (56.1\%) and right eye was operated in most of the patients (Table-I). $67.4 \%$ patients had a preoperative visual acuity of $6 / 60$ as measured on snellen's visual acuity chart which returned to $6 / 6$ in $59.8 \%$ patients one month after surgery (Table-II).

Mean age of patients in study sample was $60.24 \pm 5.540$ years. Pre-operative mean intra ocular pressure was $22.02 \pm 1.403 \mathrm{~mm} \mathrm{Hg}$ which reduced to $20.39 \pm 1.363 \mathrm{~mm} \mathrm{Hg}, 19.61 \pm 1.418 \mathrm{~mm}$ $\mathrm{Hg}, 18.94 \pm 1.738 \mathrm{~mm} \mathrm{Hg}$ after one day, one week and one month of surgery respectively (Table-III). The decrease in intraocular pressure was highly significant on statistical analysis.

\begin{tabular}{|c|l|c|c|}
\hline Sr. No & & Frequency & Percentage \\
\hline $\mathbf{1}$ & Gender & & \\
\hline i & Male & 74 & $56.1 \%$ \\
\hline ii & Female & 58 & $43.9 \%$ \\
\hline $\mathbf{2}$ & Laterality & & \\
\hline i & Left & 56 & $42.4 \%$ \\
\hline ii & Right & 76 & $57.6 \%$ \\
\hline
\end{tabular}

Table-I. Gender and laterality of patients

\begin{tabular}{|c|l|c|c|}
\hline Sr. No & Visual Acuity & Frequency & Percentage \\
\hline $\mathbf{1}$ & Pre-Operative & & \\
\hline i & $6 / 60$ & 89 & $67.4 \%$ \\
\hline ii & $6 / 36$ & 43 & $32.6 \%$ \\
\hline $\mathbf{2}$ & $\begin{array}{l}\text { 1 Month } \\
\text { Post-Operative }\end{array}$ & & \\
\hline i & $6 / 6$ & 79 & $59.8 \%$ \\
\hline ii & $6 / 9$ & 24 & $18.2 \%$ \\
\hline iii & $6 / 12$ & 17 & $12.9 \%$ \\
\hline iv & $6 / 18$ & 2 & $7.6 \%$ \\
\hline V & $6 / 36$ & 10 & $1.5 \%$ \\
\hline Table-III. Visual Acuity before and one month after \\
\hline
\end{tabular}

\section{DISCUSSION}

Kucumen RB et al studied the changes in corneal biomechanical properties and IOP after uneventful phacoemulsification and subsequent placement of intraocular lens. In their study, the intraocular pressure decreased from $17-2 \pm 3.0 \mathrm{~mm} \mathrm{Hg}$ to $15.2 \pm 3.7 \mathrm{~mm} \mathrm{Hg}$. The decrease in intraocular pressure was statistically significant $(p=0.18) .^{9}$

Dooley I et al have studied the influence of phacoemulsification cataract removal on IOP and morphology of anterior chamber of eye.

\begin{tabular}{|c|l|c|c|c|c|}
\hline Sr. No & \multicolumn{1}{|c|}{ Parameter } & Minimum & Maximum & Mean \pm Standard Deviation & P Value \\
\hline 1 & Age & 50 & 75 & $60.24 \pm 5.540$ \\
\hline 2 & Pre-Operative IOP & 20 & 25 & $22.02 \pm 1.403$ \\
\hline 3 & 1 Day Post-Operative IOP & 18 & 24 & $20.39 \pm 1.363$ & 0.000 \\
\hline 4 & 1 Week Post-Operative IOP & 16 & 24 & $19.61 \pm 1.418$ \\
\hline 5 & 1 Month Post-Operative IOP & 10 & 23 & $18.94 \pm 1.738$ \\
\hline
\end{tabular}


In their study, intra ocular pressure was measured pre operatively and post operatively and was corrected for central corneal thickness. The intraocular pressure after phacoemulsification decreased on average by $3.3 \mathrm{~mm} \mathrm{Hg} .{ }^{10}$

Bhallil S et al have studied the changes in IOP after cataract extraction with incision in clear cornea in subjects without any risk factors. In their study the intraocular pressure decreased by $2.25 \mathrm{~mm} \mathrm{Hg}$ (16\%). The researchers concluded that the decrease in intra ocular pressure was not related to thickness of natural lens but was positively associated with the change in anterior chamber depth post operatively. ${ }^{11}$

Shin $\mathrm{HC}$ et al have compared the changes in IOP after cataract surgery in patients prone to occlusion of angles versus patients with normal angles. The pre-operative intraocular pressure in patients with occludable angles was $15.77 \pm 2.20 \mathrm{~mm} \mathrm{Hg}$ versus $14.52 \pm 2.65 \mathrm{~mm} \mathrm{Hg}$ in patients with normal angles. After twelve weeks of surgery, the intra ocular pressure decreased significantly in both groups. The mean decrease was $2.31 \pm 0.99 \mathrm{~mm}$ $\mathrm{Hg}$ in the former and $0.77 \pm 1.17 \mathrm{~mm} \mathrm{Hg}$ in later. ${ }^{12}$

Altan-Yaycioglu et al have studied the IOP after cataract surgery in patients with coexisting pseudoexfoliation. They compared the intraocular parameters with a control group. In the pseudoexfoliation group, preoperative intraocular pressure was $17.3 \pm 5.4 \mathrm{mmm} \mathrm{Hg}$ which decreased to $12.8 \pm 4.0 \mathrm{~mm} \mathrm{Hg}$ at one month post operatively but increased slightly to $14.6 \pm 3.4 \mathrm{~mm} \mathrm{Hg}$ after six months of surgery. In the control group, the mean preoperative intraocular pressure was $16.1 \pm 4.2 \mathrm{mmm} \mathrm{Hg}, 12.8 \pm 3.5 \mathrm{~mm}$ $\mathrm{Hg}$ at 1 month after surgery and $14.5 \pm 2.9 \mathrm{~mm} \mathrm{Hg}$ after six months of surgery. ${ }^{13}$

Slabaugh MA et al have studied the intraocular pressure changes in patients of open angle glaucoma after phacoemulsification cataract surgery. The patients included in study did not have any history of glaucoma surgery. The mean pre-operative intraocular pressure in the study was $16.3 \pm 3.6 \mathrm{~mm} \mathrm{Hg}$ which reduced to $14.5 \pm 3.4 \mathrm{~mm}$ $\mathrm{Hg}$ after one year of cataract surgery. But $38 \%$ of the eyes required additional medical therapy for glaucoma during the study period. ${ }^{14}$

Chen PP et al have studied the literature regarding the effect of cataract surgery on intraocular pressure in diagnosed patients of glaucoma and the need for filteration surgery in such patients. The searched the Cochrane and pub med data bases and the studies relating to primary open angle glaucoma, pseudo exfoliative glaucoma and primary angle closure glaucoma without any previous filteration surgery were included. It was concluded that cataract surgery results in acute and long term reduction in intraocular pressure leading to a rarity of filteration procedure in one year post-surgery. ${ }^{15}$

Mensburger SL et al the influence of phacoemulsification on IOP in individuals with ocular hypertension. In their study, postoperative intraocular pressure was significantly lower than before surgery i.e. $19.8 \pm 3.2 \mathrm{~mm} \mathrm{Hg}$ versus $23.9 \pm 3.2 \mathrm{~mm} \mathrm{Hg} .{ }^{16}$ Yang $\mathrm{HS}$ et al have studied the biometric values of eyes after IOP lowering subsequent to phacoemulsification. They studied the axial length, corneal thickness and iris thickness after decrease in intraocular pressure as a result of phacoemulsification. They documented an $11.8 \%$ decrease in intraocular pressure three months after phacoemulsification. ${ }^{17}$

Cimetta DJ and Cimetta AC have studied the influence of phacoemulsification on IOP in eyes with pseudoexfoliation without glaucoma. They documented a mean intraocular pressure change of $-3.7 \mathrm{~mm} \mathrm{Hg}$ after three months of surgery $(p<0.0001) \cdot{ }^{18}$

Lancu $\mathrm{R}$ and Corbu $\mathrm{C}$ have studied the effect of phacoemulsification on IOP in uncontrolled open angle glaucoma patients. The mean intraocular pressure decreased by $2.1 \pm 3.7 \mathrm{~mm} \mathrm{Hg}$ at six months and by $1.9 \pm 3.9 \mathrm{~mm} \mathrm{Hg}$ after one year of surgery. ${ }^{19}$

Poley BJ et al have studied the long term effects of cataract removal by phacoemulsification on intraocular pressure. They divided the sample into subgroups according to preoperative intra 
ocular pressure. The mean change in intraocular pressure in the pre surgical group $31-23 \mathrm{~mm} \mathrm{Hg}$ was $6.5 \mathrm{~mm} \mathrm{Hg}(27 \%), 4.8 \mathrm{~mm} \mathrm{Hg}(22 \%)$ in the $22-20 \mathrm{~mm} \mathrm{Hg}$ group, $2.5 \mathrm{~mm} \mathrm{Hg}(14 \%)$ in the $19-18 \mathrm{~mm} \mathrm{Hg}$ group and $1.6 \mathrm{~mm} \mathrm{Hg}(17 \%)$ in $17-$ $15 \mathrm{~mm} \mathrm{Hg}$ group. ${ }^{20}$

\section{CONCLUSION}

Phacoemulsification cataract surgery leads to a decrease in intraocular pressure.

\section{Copyright $\Subset 25$ Sep, 2019.}

\section{REFERENCES}

1. Mastropasqua L, Toto L, Mastropasqua A, Vecchiarino L, Mastropasqua R, Pedrotti E, Nicola MD. Femtosecond laser versus manual clear corneal incision in cataract surgery. Journal of refractive surgery, 2014; 30 (1): 2733.

2. Mahmud I, Kelley T, Stowell C. A proposed minimum standard set of outcome measures for cataract surgery. JAMA Ophthalmol. 2015; 133(11):1247-1252.

3. Mahmoud J, Hesam H, Mehdi K, Mohammadkarim J, Ali T, Shadi R. Endophthalmitis occurring after cataract surgery. Ophthalmology. 2016; 123(2):295-301.

4. Gogate P, Jaggernath JB, Deshpande S, Naidoo K. Meta-analysis to compare the safety and efficacy of manual small incision cataract surgery and phacoemulsification. Middle East Afr J Ophthalmmol 2015; 22:362-9.

5. Agarwal A, Jacob S. Current and effective advantages of Femto-phacoemulsification. Cur Opin Ophthalmol $2017 ; 28: 49-57$.

6. Irak-Dersu I, Nilson C, Zabriskie N, Durcan J, Spencer $\mathrm{HJ}$ et al. Intraocular pressure change after temporal clear corneal phacoemulsification in normal eyes. Act Ophthalmol. 2010; 88(1):131-134.

7. Dawczynski J, Koenigsdoerffer E, Augsten R, Strobel J. Anterior segment optical coherence tomography for evaluation of changes in anterior chamber angle and depth after intraocular implantation in eyes with glaucoma. Eur J Ophthalmol. 2007; 17(3):363-7.

8. Hayashi K, Hayashi H, Nakao F, Hayashi F. Changes in anterior chamber angle width and depth after intraocular lens implantation in eyes with glaucoma. Ophthalmology. 2000; 107(4):698-703.
9. Kucumen RB, Yenerel NM, Gorgun E, Kulacoglu DN, Oncel B et al. Corneal biomechanical properties and intraocular pressure changes after phacoemulsification and intraocular lens implantation. J Cat \& Ref Surg. 2008; 34(12):20962098.

10. Dooley I, Charalampidou S, Malik A, Loughman J, Molly $L$ et al. Changes in intraocular pressure and anterior segment morphometry after uneventful phacoemulsification cataract surgery. Eye. 2010; 24:519-527.

11. Bhallil S, Andalloussi IB, Chraibi F, Daoudi K, Tahri H. Changes in intraocular pressure after clear corneal phacoemulsification in normal patients. Oman $\mathrm{J}$ Ophthalmol. 2009; 2(3):111-113.

12. Shin HY, Subrayan V, Tajunisah I. Changes in anterior chamber depth and intraocular pressure after phacoemulsification in eyes with occludable angles. J Cat \& Ref Surg. 2010; 36(8):1289-1295.

13. Altan-Yaycioglu $R$, Canan $H$, Pelit A, Akova YA. Intraocular pressure after phacoemulsification in eyes with pseudoexfoliation. J Cat \& Ref Surg. 2009; 35(5):952-954.

14. Slabaugh MA, Bojikian KD, Moore DB, Chen PP. The effect of phacoemulsification on intraocular pressure in medically controlled open angle glaucoma patients. Am J Ophthalmol. 2014; 157(1):26-31.

15. Chen PP, Lin SC, Junk AA, Radhakrishnan S, Singh K et al. The effect of phacoemulsification on intraocular pressure in glaucoma patients: A report by American Academy of Ophthalmology. Ophthalmology. 2015; 122(7):1294-1307.

16. Mansburger SL, Gordon MO, Jampel H, Bhorade A, Brandt JE et al. Reduction in intraocular pressure after cataract extraction: The ocular hypertension treatment study. Ophthalmology. 2012; 119(9):18261831.

17. Yang HS, Lee J, Choi S. Ocular biometric parameters associated with intraocular pressure reduction after cataract surgery in normal eyes. Am $\mathrm{J}$ Ophthalmol. 2013; 156(1):89-94.

18. Cimetta DJ, Cimetta AC. Intraocular pressure changes after clear corneal phacoemulsification in non glaucomatous pseudoexfoliation syndrome. Eur J Ophthalmol. 2008; 18(1). doi. org/10.1177/112067210801800113.

19. Lancu R, Corbu C. Intraocular pressure after phacoemulsification in patients with uncontrolled primary open angle glaucoma. J Med Life. 2014; 7(1):11-16. 
20. Poley BJ, Lindstrom RL, Samuelson TW. Long term effects of phacoemulsification with intraocular lens implantation in normotensive and ocular hypertensive eyes. J Cat \& Ref Surg. 2008; 34(5):735742.

\begin{tabular}{|c|c|c|c|}
\hline \multicolumn{4}{|c|}{ AUTHORSHIP AND CONTRIBUTION DECLARATION } \\
\hline Sr. \# & Author(s) Full Name & Contribution to the paper & Author(s) Signature \\
\hline 1 & Rizwan Ahmed & $\begin{array}{l}\text { Research idea conception, } \\
\text { Performing surgery, Critical review. }\end{array}$ & \\
\hline 2 & Muhammad Shaheer & $\begin{array}{l}\text { Performing surgery, Data } \\
\text { collection, Writing of paper draft. }\end{array}$ & \\
\hline 3 & Arooj Amjad & $\begin{array}{l}\text { Data collection and analysis, } \\
\text { Literature review. }\end{array}$ & \\
\hline 4 & Talha & Data analysis, Literature review. & \\
\hline 5 & Hina Mehmood & Data analysis, Literature review. & \\
\hline 6 & Ayesha Ahmad & Data analysis, Literature review. & \\
\hline
\end{tabular}

